\title{
The balancing act: the variation among deaneries across Great Britain regarding provision of focus on diabetes and endocrinology training
}

\author{
ADNAN AGHA, ${ }^{1}$ BALDEV M SINGH, ${ }^{2}$ WASIM HANIF ${ }^{3}$
}

\begin{abstract}
Diabetes and endocrinology is a medical specialty, and a fiveyear dual accreditation training programme in diabetes and endocrinology and general internal medicine is offered, with active participation in medical on-call rota. Some deaneries offer some respite from the ever-increasing general medical workload by offering a few months of training focusing only on specialty work in diabetes and endocrinology. The authors wanted to see if this experience is available uniformly to all the trainees in diabetes and endocrinology/ general internal medicine across Great Britain. To assess this, a survey of specialist training registrars on a dual accreditation programme for diabetes and general internal medicine from all deaneries in England, Scotland and Wales was performed by directly interviewing and asking them about any relaxation in either their on-call or ward commitments to focus on diabetes and endocrine specialty during their five years of training. The results showed that the acute take/general medical commitment-free training period focusing only on diabetes and endocrinology ranges from zero in some deaneries to nearly three years in others. This simple survey highlights the extent of variability that exists in dual diabetes/endocrinology and general internal medicine training programmes across deaneries in England, Scotland and Wales, which may increase further once the training programme is reduced to four years after new changes from Shape of Training.

Br J Diabetes 2018;18:22-24
\end{abstract}

Diabetes \& Endocrinology Department, Russell Hall, Dudley Group of Hospitals, UK

Royal Wolverhampton NHS Trust, Wolverhampton, UK

Department of Diabetes, University Hospital Birmingham, Birmingham, UK

Address for correspondence: $\operatorname{Dr}$ Adnan Agha

Specialist Registrar, Diabetes \& Endocrinology Department, Russell Hall,

Dudley Group of Hospitals, UK

Tel: +44 (0)1384 456111 Ext 3691

E-mail: adnanagha@hotmail.com

https://doi.org/10.15277/bjd.2018.158
Key words: specialist training registrar (StR), diabetes and endocrinology (D\&E), general internal medicine (GIM), training programme, deanery

\section{Introduction}

Diabetes and endocrinology is a medical specialty with 444 trainee registrars and 1,178 consultants at present in United Kingdom. ${ }^{1}$ Diabetes training involves two years in a foundation programme followed by seven years of specialist training, including two years of core medical training (specialist training (CT/ST) years 1-2) and five years of higher training (specialist training years 3-7), leading to a certificate of completion of training in diabetes and endocrinology along with level 2 competency in acute medicine. ${ }^{2}$ Over the last six years the competition ratio of the specialty has fallen from 2.2 to 1.2 candidates per post. ${ }^{3}$ Unlike some other medical specialties, diabetes and endocrinology (D\&E) trainees participate actively in the acute medical take rota as well as general internal medicine (GIM) commitments as medical registrars, which the Royal College of Physicians (RCP) considers as the medical 'workhorse' of the hospital who are relied upon quite heavily, mentioning a greater role for general medical registrars and ways to maximise their clinical experience and training. ${ }^{4,5}$ However, in the dual specialty training programme the pressure on medical registrars can take its toll on training, and D\&E can get less focus due to service provision commitments with the ever-increasing pressures on the NHS resulting from the developing workforce crisis, unsociable rotas and less favourable training environment (eg, 1:6 on-call rota with mandatory rest days and leaves can reduce specialty training time by up to half). There is already a huge disparity between the demand for medical specialties that include GIM commitments compared with those that do not - for example, in 2010 only four of 13 deaneries filled all their specialist training year posts in D\&E/GIM, in complete contrast to dermatology (that does not include GIM commitments) where no vacant posts were available nationally. ${ }^{6}$ Although the RCP recommends GIM exposure for all trainees in all medical specialties to have a more even distribution of GIM workload, data from the RCP suggest that specialties with a low GIM component, such as genitourinary medicine and infectious diseases, attract the highest calibre applicants, as shown by the proportion deemed appointable and their standard interview scores compared with specialties with a higher GIM on-call commitment such as acute medicine and D\&E (see Figure 1). 
Figure 1. Bar chart (based on data from the Royal College of Physicians) showing the specialty trainee interview score and percentage of candidates deemed appointable by the specialty

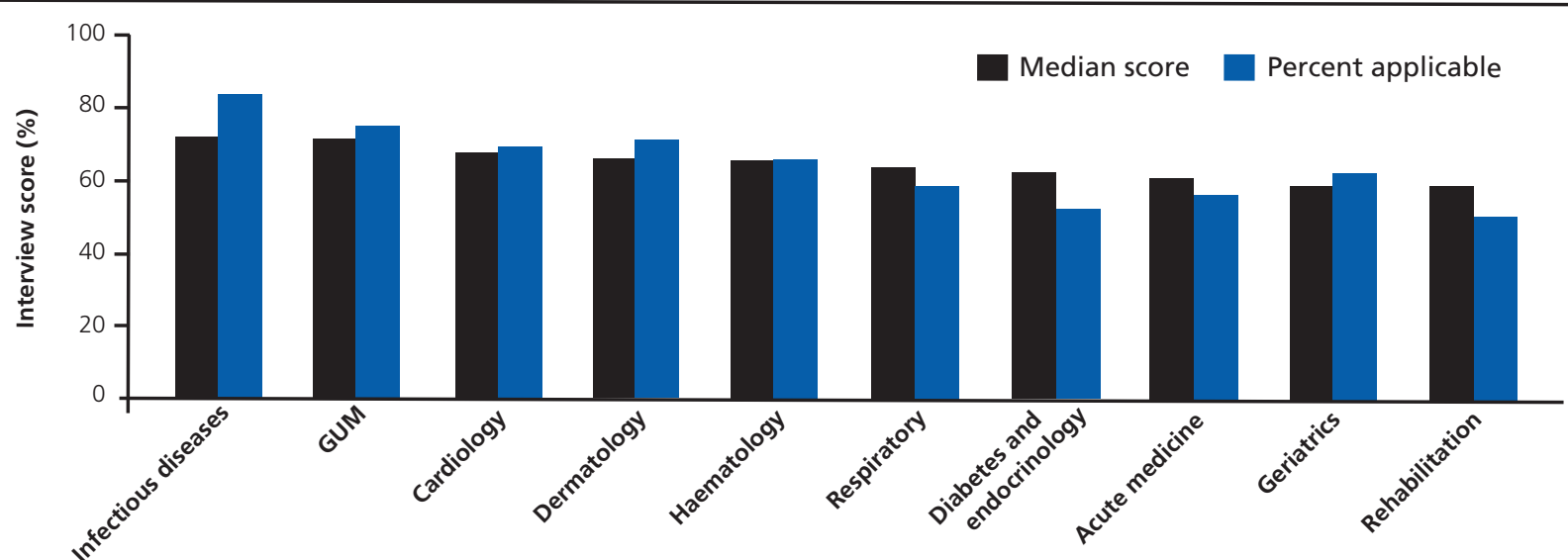

The authors wanted to see if there is any GIM-free time provided to trainees of D\&E/GIM across the various deaneries and whether this experience is available uniformly to all trainees. A survey was carried out to determine if dual specialty trainees in GIM (which in itself as a lone specialty has a three-year training requirement only) and $D \& E$ (which on its own has four years training only) get a GIM-free period in their five-year training programme to focus on D\&E alone.

\section{Methods}

A minimum of two specialist training registrars (StR) on dual accreditation programmes for GIM/D\&E from each of the East Midlands, East of England, Kent Sussex Surrey, Northern, Mersey, North West, Peninsula, Severn, Thames Valley, Wessex, West Midlands, Yorkshire, London, Scotland and Wales deaneries were interviewed face to face and data recorded. They were asked about their deanery and confirmed if they were on a dual CCT accreditation programme. StRs' responses from those out of the programme were excluded from the data collection. The participants were then asked two questions:

- During the five years of dual training, how many months of reduced acute take/medical on-call commitments are given to the trainee during the programme to focus on D\&E specialty work?

- During the five years of dual training, how many months of reduced GIM/ward commitments are given to the trainee to focus on D\&E specialty work?

This exercise of directly interviewing GIM/D\&E StRs was done by one of the authors at national training events of the Diabetes UK Annual Professional Conference 2016 and the Society for Endocrinology Clinical Update 2016 meeting over a period of five months. As it was a general survey about training, no ethical approval was required/obtained.

\section{Results}

The results did show some lack of homogeneity among deaneries in relation to concentrating on D\&E specialty training (Table 1). Although all trainees are on National Training Number for
$D \& E$, their GIM-free training period concentrating only on D\&E is widely different, ranging from none to nearly three years. Based on this, the number of months with reduced GIM on-call commitments may almost double the exposure time for specialty training in D\&E. Also, the deaneries' fill rates for D\&E seem to

Table 1 General internal medicine (GIM)-free period and reduced acute take provision by deaneries across Great Britain during five-year dual specialty programme in diabetes and endocrinology (D\&E)/GIM

\begin{tabular}{|c|c|c|c|}
\hline Region/deanery & $\begin{array}{l}\text { Reduction of } \\
\text { on-calls/acute } \\
\text { medical take* }\end{array}$ & $\begin{array}{l}\text { GIM/ward- } \\
\text { free period } \\
\text { to focus on } \\
\text { D\&E }\end{array}$ & $\begin{array}{l}\% \text { NTN } \\
\text { filled in } \\
2015 \\
\text { round }\end{array}$ \\
\hline East Midlands & 0 month & 0 month & $100 \%$ \\
\hline East of England & 0 month & 0 month & $40 \%$ \\
\hline Kent Sussex Surrey & 0 month & 18-24 months & $89 \%$ \\
\hline Northern & 0 month & 0 month & $100 \%$ \\
\hline Mersey & 0 month & 0 month & $100 \%$ \\
\hline North West & 12 months $^{\dagger}$ & 12 months $^{\dagger}$ & $100 \%$ \\
\hline Peninsula & 0 month & 0 month & $100 \%$ \\
\hline Severn & 0 month & 0 month & $71 \%$ \\
\hline Thames Valley & 24 months & 24 months & $100 \%$ \\
\hline Wessex & 0 month & 20 months & $57 \%$ \\
\hline West Midlands & 0 month & Up to 3 months $^{\dagger}$ & $100 \%$ \\
\hline Yorkshire & 0 month & 12 months & $55 \%$ \\
\hline London & 0 month & 24 months & $100 \%$ \\
\hline Scotland & 24-36 months & 24-36 months & $100 \%$ \\
\hline Wales & 0 month & Up to 8 months & $67 \%$ \\
\hline \multicolumn{4}{|c|}{$\begin{array}{l}\text { *At least } 50 \% \text { reduction in usual on-call shifts per cycle. } \\
\text { tOnly one hospital offers this provision and all candidates may not have the same } \\
\text { opportunity. } \\
\text { NTN, national training number }\end{array}$} \\
\hline
\end{tabular}




\section{Key messages}

- Huge variability exists in the structure of programmes of training in diabetes and endocrinology (D\&E) combined with general internal medicine (GIM) among deaneries in England, Scotland and Wales

- Some deaneries offers more general medical commitment-free training period while focusing on diabetes and endocrinology (up to 36 months) while others do not offer it

- The best mix of speciality training should be debated and evolved

be different - for example, all three deaneries that offer reduced on-call commitments had a 100\% fill rate compared with 11 other deaneries which did not offer reduced on-call commitments, of which six (54\%) had a fill rate of less than $100 \% .^{7}$ This may be entirely coincidental or related to a number of factors.

\section{Discussion}

It is very difficult to construct a discussion from these data, but it raises questions as to the mechanisms by which deaneries have come to focus on either D\&E or GIM and how GIM service provision is allocated throughout the five years of dual accreditation training.

Surely we can agree that the purpose of training is to make an StR fit for purpose as a consultant. Thus, we can agree that training in diabetes, endocrinology, acute and general medicine is required. The issue is that there is variability, not that it is right or wrong to have this in the mix. The authors are not implying that there should be homogeneity amongst deaneries - indeed, variation may offer choice to trainees - but there ought to be some notion of the relationship between experience mix, training needs and of the intended outcomes in relationship to CCT attainment and consultanthood.

We do not think there is any evidence to inform decision making. For example, is there any evidence that the various programmes with their variable balance produce an associated variability in the quality of output? We don't necessarily expect that trainee satisfaction would be a measure by which to judge programme structure. Furthermore, the application of the Kilpatrick principles relating to evaluation and assessment would only be meaningful after training has been completed. ${ }^{8}$ Even then, no trainee would have experience of a full programme between programmes. Fill rates have gone down in many medical specialties, not just $D \& E$, and there is manifestly no relationship between these and quantity of GIM. The trainee satisfaction survey, trainee fill rates, Specialty Certificate Examination pass rate and consultant post appointments are dependent on so many variables that they may not be expected to correlate with this variability in training, and our view is that even attempting to use them as tools is probably doomed to failure or spurious association in recompense for what would be a huge effort.

This survey has some limitations. The data are based on trainee feedback and information given by them rather than data provided from official deaneries which, to the best of the authors' knowledge, was not fully available on any deanery website or resource at the time of writing. We therefore only have a trainee perspective of the specialty training rather than the deaneries' view. Also, the Northern Ireland deanery data were missing in this survey.

\section{Conclusion}

This simple survey highlights the magnitude of variability in the structure of programmes of training in D\&E combined with GIM between deaneries in England, Scotland and Wales, which is likely to have arisen historically without due consideration for the purpose of training - which is to produce doctors able to safely and competently take up a consultant post. The actual measure of what is the best mix of training is unknown, but surely it should be debated and evolved by those invested with accountability and responsibility for these programmes. Furthermore, with the new Shape of Training on the horizon ${ }^{9}$ and the specialist training period for D\&E being reduced to four years instead of five, it is likely to make the variation among deaneries to provide exposure time for specialist training in D\&E even greater.

\section{Conflict of interest None Funding None}

All three authors contributed equally to this work and are based in NHS West Midlands.

\section{References}

1. Census of consultant physicians and higher specialty trainees in the UK. RCP London Workforce. Published 28 June 2017. Available at https://www. rcplondon.ac.uk/projects/outputs/2016-17-census-uk-consultants-andhigher-specialty-trainees.

2. Mettayil J, Quinton R, Wahid D. Careers in diabetes and endocrinology BMJ Careers, 2008. http://careers.bmj.com/careers/advice/Careers_in_ diabetes_and_endocrinology

3. Royal College of Physicians (RCP). ST3 recruitment. Application numbers, post numbers, competition ratios. London: RCP, 2016. http://www.st3recruitment.org.uk/specialties/endocrinology-diabetes

4. Royal College of Physicians (RCP). The medical registrar: empowering the unsung heroes of patient care. London: RCP, 2013. https://www.rcplondon.ac.uk/sites/default/files/future-medicalregistrar_1.pdf

5. Royal College of Physicians (RCP). Acute care toolkit 8: The medical registrar on call: maximising clinical experience, training and patient care. London: RCP, 2013. https://www.rcplondon.ac.uk/sites/default/files/act8_registrars. pdf

6. Centre for Workforce Intelligence. Endocrinology and diabetes mellitus CfWI medical fact sheet and summary sheet. August 2011.

7. Royal College of Physicians (RCP). Round 2 ST3 recruitment interview scores. London: RCP, 2012. http://www.st3recruitment.org.uk/documents/r2-totalscores.html

8. Bates R. A critical analysis of evaluation practice: the Kirkpatrick model and the principle of beneficence. Evaluation and Program Planning 2004; 27:341-7. https://doi.org/10.1016/j.evalprogplan.2004.04.011

9. Greenaway D, ed. Securing the future of excellent patient care, 2013. http://www.voced.edu.au/content/ngv:64322 